\title{
John Powell \\ CODIFICATION OF RESEARCH ON THE CONE-PENETRATION \\ TESTING OF SOILS (Information)
}

A lecture delivered by Professor J. J. M. Powell was devoted to equipment for cone- penetration testing of soils. The evolution of cone-penetration devices is traced from manual equipment through mechanized systems. Examples are presented for horizontal cone-penetration testing in an underground tunnel, and methods of determining the frontal resistance to the cone and the friction against the coupling with consideration of a correction for pore pressure.

It is demonstrated that the method used for cone-penetration testing (CPT), particularly when a piezoconus (CPTU) is employed, is an excellent tool for stratigraphic profiling (plotting of geologicengineering sections) with consideration of fundamental behavioral characteristics of the soils, filtration of water, the drained and undrained state of the soils, the behavior of sands and clays subject to shear in the undrained state, and all parameters that can be obtained.

A testing unit utilizing a conical pressiometer is described. Nonlinear relationships of soil mechanics are used for interpretation of the results.

Data derived from field tests of soils should be used for design, thereby reducing the level of uncertainty during design, where empirical relationships are employed for interpretation of test data.

Cone-penetration testing is a powerful tool that will yield reliable results with the proper testing unit and use. The method can be used for the design and analysis of foundations.

Translated from Osnovaniya, Fundamenty i Mekhanika Gruntov, No. 6, pp. 15-16, November-December, 2009. 